\title{
RELATÓRIO DOS EGRESSOS DA ENGENHARIA DE PRODUÇÃO DA UFSJ
}

\author{
Felipe Alexandre de Souza Félix Nunes ${ }^{(1)}$ (asfn@adm.mest.ufmg.br) \\ (1) Universidade Federal de Minas Gerais (UFMG) - CEPEAD - Avenida Presidente Antônio Carlos, 6627 - Pampulha - BH - MG
}

RESUMO: Este artigo trata-se de um levantamento dos egressos do curso de Engenharia de Produção da Universidade Federal de São João del-Rei. Discute-se a evolução da engenharia no Brasil, desde o estabelecimento da primeira escola do tipo, ainda no período colonial, as modificações provocadas pela evolução da sociedade ao longo do tempo, até a instituição das primeiras faculdades de Engenharia de Produção plena. Toda essa transformação também provocou uma modificação do perfil exigido do profissional da engenharia, solicitando dos recém-formados habilidades, atitudes e conhecimentos diferentes do que apenas a compreensão técnica. Para este trabalho utilizou-se dados obtidos por meio de relatórios oficiais do governo federal, análise do Projeto Pedagógico do Curso, e coleta de dados obtidos em divulgação pelas redes sociais públicas. As informações foram reunidas para facilitar o planejamento dos próximos anos da graduação, para que esse trabalho seja um documento orientador para futuras direções do ensino superior voltado a capacitar um profissional cada vez mais multidisciplinar.

PALAVRAS-CHAVE: engenharia, educação, produção, multidisciplinaridade, egressos

\section{INTRODUÇÃO}

A primeira escola de engenharia do Brasil remete ao período colonial e até a década de 1930 não haviam mais do que 30 cursos em funcionamento no país (BITTENCOURT; VIALI; BELTRAME, 2010). Se até hoje a Universidade Federal do Rio de Janeiro, e o Instituto Militar de Engenharia discutem quem são os herdeiros da Real Academia de Artilharia, Fortificação e Desenho (CARUSO, 2008), outras escolas se instituíram, cresceram e se estabeleceram como opções para formação em engenharia.

A instrução do engenheiro é um tema que tem sido discutido recentemente na ciência (BATTISTI; NEHRING, 2019; SIMÓN, 2018) não só no Brasil, mas em vários países. Isso porque as exigências do mercado, assim como as transformações da sociedade impuseram um novo perfil profissional, um engenheiro que não se limita aos conhecimentos técnicos, mas às necessidades de um comportamento positivo em âmbito social, ambiental e político.

Isso é trazido neste trabalho em um levantamento da situação atual de egressos do curso de Engenharia de Produção da Universidade Federal de São João del-Rei. Uma leitura de como o mercado tem direcionado esses profissionais e que cargos eles estão ocupando. Uma percepção de que, para o engenheiro de produção moderno é necessário construir o conhecimento de maneira multidisciplinar, com elementos das ciências sociais e humanas. Pretende-se atualizar as exigências da formação, oferecendo aos responsáveis pelo curso na UFSJ ideias para disciplinas optativas que consigam promover em futuros estudantes os conceitos exigidos nas empresas que absorvem esses profissionais recém-formados.

\section{REFERENCIAL TEÓRICO}



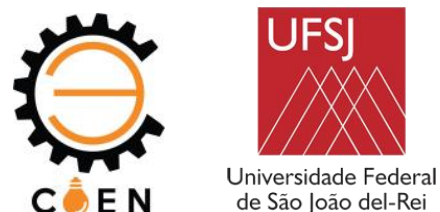

\subsection{Engenharia no Brasil}

A trajetória dos cursos de engenharia no Brasil tem como marco a criação da Real Academia de Artilharia, Fortificação e Desenho na cidade do Rio de Janeiro em 1792, considerada a primeira escola de engenharia do continente americano. Sua criação foi inspirada na organização de mesmo nome instituída por D. Maria I (1734 - 1816), Rainha de Portugal, em Lisboa no ano de 1790 (FIOLHAIS; SIMÕES; MARTINS, 2013).

Em Minas Gerais se encontram quatro das mais antigas instituições de ensino de engenharia do Brasil. A mais longínqua é a Escola de Minas de Ouro Preto, fundada em 1874 e tratada como a segunda escola de engenharia do país. As outras academias que compõem esta seleta listagem são o Instituto Politécnico em Juiz de Fora (1909), a Escola Livre de Engenharia em Belo Horizonte (1911) e o Instituto Eletrotécnico de Itajubá datada de 1913 (OLIVEIRA et al., 2013).

Em meados dos anos 90 a abertura de cursos de engenharia teve um crescimento exponencial. A média de criação de novos cursos saltou de 12 novos cursos por ano, para aproximadamente 80 novos cursos no período entre 1997 e 2005 . De 2005 em diante a média subiu de mais de 100 cursos por ano para mais de 200 cursos criados (OLIVEIRA et al., 2013). A formação e o exercício profissional do engenheiro também foram modificados, o que determinou o surgimento de novas modalidades.

A motivação para isso se deu em 1996, com a aprovação de uma nova Lei de Diretrizes Básicas (LDB n ${ }^{\circ} 9.394$ de 20 de dezembro de 1996) que impulsionou o crescimento do número de cursos no ensino superior. Aliado à transformação da formação e o exercício profissional em Engenharia a partir da segunda metade do Século XX, implicou no surgimento de novas categorias. No ano de 1995 haviam cerca de 30 modalidades com mais de 50 ênfases distintas em engenharia, inteirando praticamente 90 titulações diferentes. Atualmente a quantidade de títulos distintos é mais que o dobro, com quase 250 qualificações alternativas registradas no Ministério da Educação e o Conselho Federal de Engenharia acomodando-as em 100 habilitações profissionais em Engenharia (OLIVEIRA et al., 2013).

O profissional de Engenharia exerce, na maioria das vezes, atividades de gerenciamento e administração, embora apenas depois da década de 1950 os currículos de Engenharia passaram a ter disciplinas destas áreas. A partir da década de 1960 a gestão da produção passou a ter destaque de cursos tradicionais como Engenharia Mecânica e Civil. Ainda assim a criação dos primeiros cursos de Engenharia de Produção (EP) plenos, na USP e na UFRJ, demorou até o início da década de 1970 (FLEURY, 2008; OLIVEIRA, 2010).

Em se tratando de engenharia de produção a primeira instituição de ensino do país a oferecer o curso foi a Escola Politécnica da Universidade de São Paulo em 1958, como opção do curso de Engenharia Mecânica. Em 1967 a Faculdade de Engenharia Industrial de São Bernardo do Campo abriu o seu curso, seguido pela Universidade Federal do Rio de Janeiro em 1968 (BITTENCOURT; VIALI; BELTRAME, 2010).

A evolução dos cursos de engenharia de produção no país se deu na mesma proporção. Se no início dos anos de 1990 o Brasil contabilizava 15 cursos este número alcançou 72 no ano 2000, quase 300 cursos em 2008 (BITTENCOURT; VIALI; BELTRAME, 2010) e hoje contabiliza mais de 800 cursos de Engenharia de Produção, oferecidos por 614 instituições diferentes, sendo 79 instituições públicas e 535 escolas privadas (INEP, 2018). 

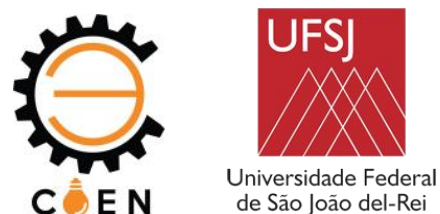

O trabalho de Oliveira et al. (2013) listou o crescimento das dez principais modalidades de engenharia no Brasil entre 2001 e 2011. Ainda que tenha se estabelecido recentemente, em comparação à outras habilitações, a Engenharia de Produção "plena" é a modalidade que possui a maior quantidade de cursos, superando a tradicional Engenharia Civil, embora esta última ainda detenha a maior quantidade de ingressantes e a maior taxa de ocupação de vagas.

Em Minas Gerais, nos dados divulgados pela última avaliação do Conceito Preliminar do Curso (CPC) promovido pelo Ministério da Educação (INEP, 2018), são 81 cursos ditos Engenharia de Produção plena entre Centros Universitários, Faculdades, Institutos e Universidades, públicos e privados. Em relação às Instituições de Ensino Superior (IES) de âmbito público no estado de Minas Gerais encontram-se 17 cursos de EP em 11 instituições.

\subsection{Obstáculos da formação}

Um tópico recorrente nos estudos sobre o ensino da Engenharia é a taxa de evasão, obtida ao confrontar-se a quantidade de alunos ingressantes em um ano com os alunos que concluíram o curso no ano previsto. O trabalho de Oliveira et al. (2013) estimou, em média, seis anos o prazo para concluir o curso universitário sendo que nas universidades públicas a média geral é de sete anos.

Nesse estudo, organizado com a base de dados do INEP, a estimativa do percentual de evasão anual encontra-se em um patamar acima de 50\%, entre 1995 e 2002, oscila próximo desse valor até o ano de 2009 e cai rente aos $40 \%$ de abdicação nos últimos dois anos do levantamento, entre 2009 e 2011 (OLIVEIRA et al., 2013).

Outro estudo de Oliveira (2010) reforça dados para a evasão média indicada como próxima ao patamar de $50 \%$, em que as universidades privadas são responsáveis por uma taxa de evasão acima de $60 \%$ enquanto as escolas de engenharia da rede pública se encontram próximas aos $40 \%$ de abandono.

Para este trabalho recorreu-se à mesma fonte de dados, na página do Instituto Nacional de Estudos e Pesquisas Educacionais Anísio Teixeira (INEP) apresentados como "Sinopse da Educação Superior". Com informações disponíveis em planilhas atualizou-se essa interpretação voltando-se apenas para o objeto desse estudo, especificamente a Engenharia de Produção nas universidades públicas.

Tradicionalmente se destina à integração do curso dez períodos letivos (cinco anos), tendo Oliveira et al. (2013) indicado seis anos em geral e sete anos para universidades públicas, este trabalho comparou entradas e saídas para todos os três parâmetros - cinco, seis e sete anos - e utilizou a porcentagem média entre as configurações.

Para uma primeira comparação trabalhou-se com ingressantes e concluintes de cursos com a denominação Engenharia de Produção e suas diversas modalidades - plena, elétrica, civil, mecânica, de materiais, química, têxtil, mecânica, industrial, metalúrgica e de energia - na rede de IES públicas. A estimativa de evasão média encontrou patamares relativamente altos para esse indicador. 


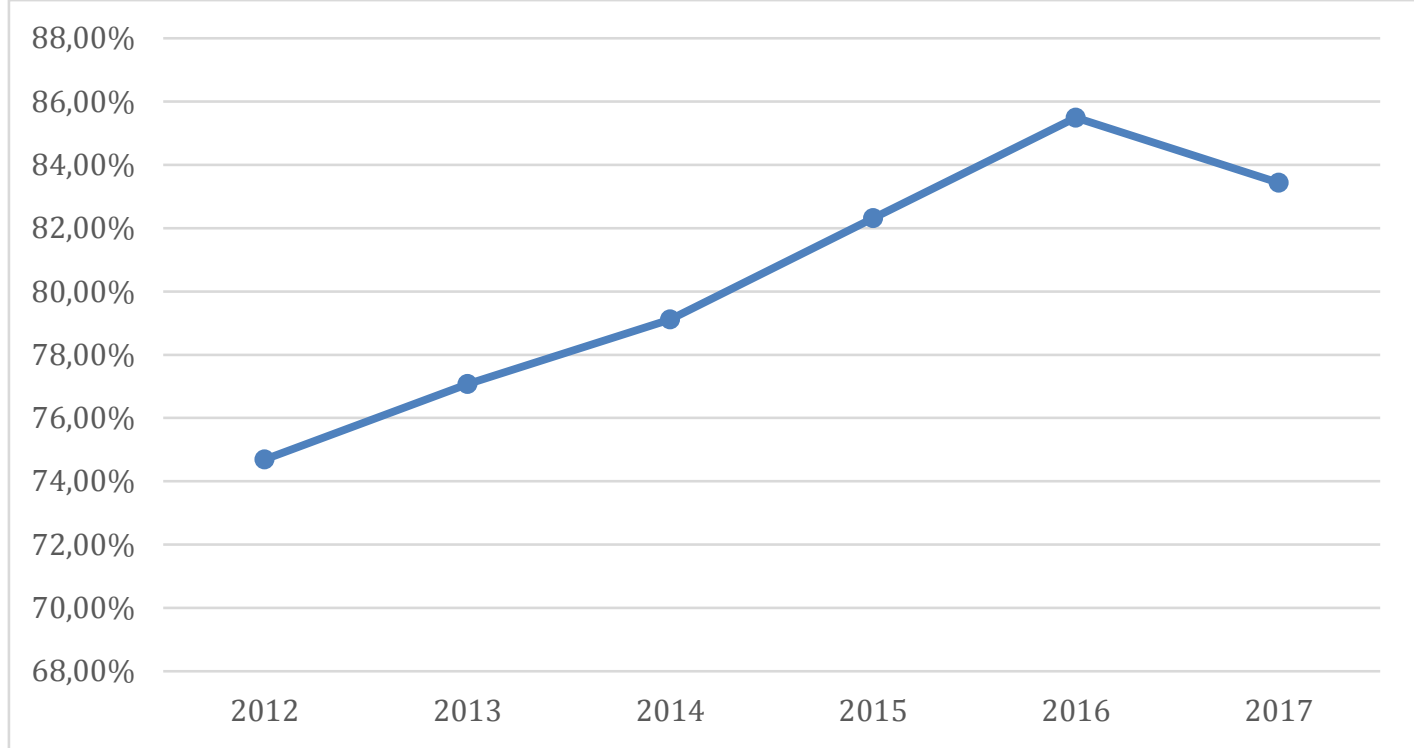

Figura 1. Estimativa de evasão anual na Engenharia de Produção plena e modalidades (Fonte: Organizado pelo autor com base nos dados disponibilizados no Portal do INEP (2019))

Considerando-se o número de ingressantes em comparação com o número de alunos egressos - cinco, seis e sete anos depois - apenas dos cursos de Engenharia de Produção plena nas universidades públicas brasileiras, a estimativa de evasão segue uma mesma curva ascendente.

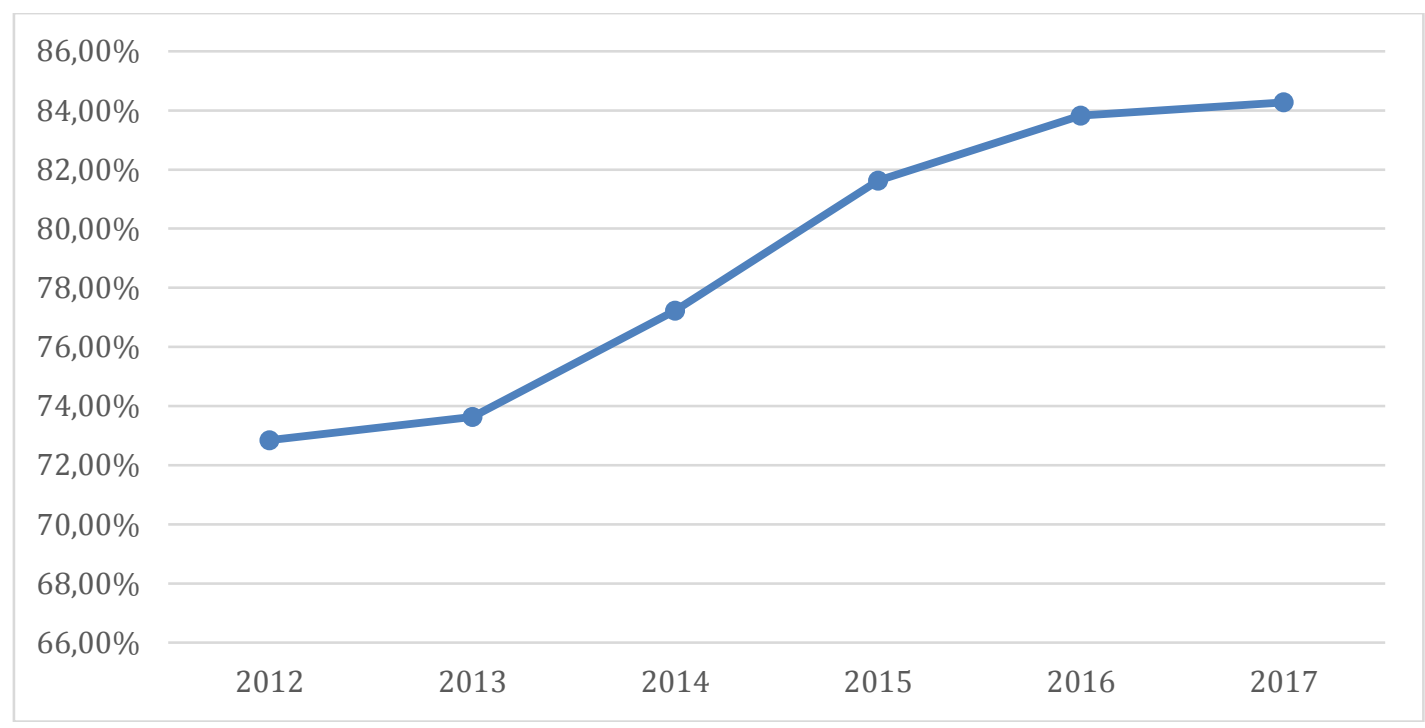

Figura 2. Estimativa de evasão anual na Engenharia de Produção plena (Fonte: Organizado pelo autor com base nos dados disponibilizados no Portal do INEP (2019)) 

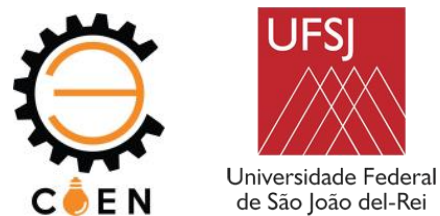

Em questões comparativas os trabalhos de Oliveira (2010) e Oliveira et al. (2013) tratam de todos os cursos de engenharia. Ainda assim as evidências do crescimento dos índices de evasão soam o alarme para os obstáculos na eficácia da formação profissional no país. É possível sugerir alguns motivos, como o aumento da taxa de indivíduos desempregados no país de 4,80\% em 2014 para 12,70\% em 2017 (IBGE, 2018) atribuída à crise econômica e política do país, mas para que haja confirmação dessa relação são precisos outros estudos.

Este trabalho abordará uma outra ideia, trata-se de uma análise das demandas profissionais do atual mercado de trabalho e do perfil do engenheiro moderno, com enfoque no perfil do engenheiro de produção. A proposta é no sentido da eficácia da formação, uma vez que os índices de evasão cresceram. Dentro do Projeto Pedagógico do Curso a Coordenadoria de Engenharia de Produção (COENP) da UFSJ propõe o entendimento desta sazonalidade do mercado, seguindo novas tendências e exigências. O ensino de conteúdos cujo aproveitamento no ambiente de trabalho seja cada vez maior precisa ser realizado sem descartar as características principais do engenheiro brasileiro, oriundos de uma escola centenária e cuja imagem está enraizada na sociedade.

\subsection{A formação do engenheiro}

Em Instituições de Ensino Superior (IES) as propostas dos cursos de nível superior objetivam a formação profissional e são normatizadas por arranjo social elaborado pela sociedade. Do acadêmico formado se espera condições mínimas para a execução da atividade profissional, aliada a habilidades racionais e emocionais e capacidade do exercício da cidadania (BATTISTI; NEHRING, 2019).

O perfil da formação em Engenharia é descrito nas Diretrizes Curriculares Nacionais, indicase que o aluno receba uma formação generalista que o permita desenvolver novas tecnologias e desempenhar uma função crítica na solução de problemas de espectro políticos, econômicos, sociais etc. (BRASIL, 2002). Desta maneira tem-se como objetivos desenvolver, entre habilidades e competências, conhecimentos matemáticos, científicos e tecnológicos para identificar e resolver problemas, avaliando o impacto das atividades no contexto social e ambiental (BRASIL, 2002).

Alguns autores detectaram um deslocamento de engenheiros para ocupações não específicas de engenharia, o que pode ser um indicador de que há profissionais suficientes para as demandas atuais (NASCIMENTO et al., 2011). Outros estudos também apontam para essa linha, noticiando a contratação de engenheiros pelo setor financeiro, comercial e muitos profissionais listados como gestores e empreendedores de organizações que prestam serviços diversos, além de empresas que prestam serviços de engenharia (OLIVEIRA et al., 2013).

Maciente; Araújo (2011) apontam que a cada dois graduados em engenharia trabalhando atualmente, em regime de CLT, em ocupações típicas de suas formações há outros cinco que não exercem tais ocupações. Se ainda não há dados oficiais que corroborem essa proporção em outros países, mesmo que haja indicações, também não existe ideia se o perfil da formação do engenheiro brasileiro o capacita a atuar com domínio em outras atividades.

Certos trabalhos internacionais sobre o futuro da educação superior entendem que os graduados possuam capacidades genéricas e que atravessem múltiplas disciplinas, tendo noções em campos de conhecimento que integram a base de várias capacidades profissionais (SIMÓN, 2018). Essa proposta de formação multidisciplinar iniciou em meados da década de 1990 e cresceu com a 

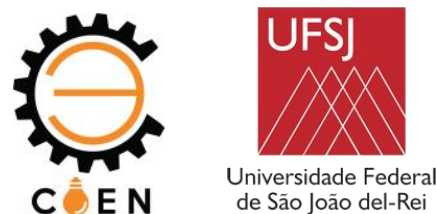

transformação provocada pelo desenvolvimento tecnológico e mudanças organizacionais nas empresas (SIMÓN, 2018).

Em nível global o cenário da educação superior segue a tendência da formação multidisciplinar, ou seja, busca-se que os profissionais conheçam e apliquem métodos e técnicas de outras áreas que lhes sirvam de apoio profissional (DAMIÁN, 2016). Na engenharia o cenário não é diferente, Sáez (2004) fala em formar o "Engenheiro Sociotécnico", fragmentando o curso de disciplinas meramente técnicas e identificando as necessidades de um profissional multifuncional.

A preocupação com a formação do engenheiro é uma discussão de âmbito internacional, com trabalhos em diversos países compreendendo que o perfil deste profissional deva ser criativo, inovador, de alta capacidade de comunicação e de espirito empreendedor e empresarial (ACOFI, 2007; UNESCO, 2010). Desta maneira torna-se mais evidente a necessidade de que as universidades realizem mudanças curriculares, no sentido de formar engenheiros cada vez mais propensos a responder as necessidades da sociedade.

Trabalhos europeus como os de Ruiz $(1998,2004)$ identificaram que egressos de Engenharia Industrial - descritos como profissionais que supervisionam processos produtivos em plantas industriais - eram direcionados a assumir cargos de gestão nas áreas financeiras-administrativas. Desta maneira esses profissionais não poderiam resolver os problemas apenas de maneira técnica, mas também com conhecimentos oriundos das ciências sociais.

A diferença na abordagem curricular, no contexto latino-americano, foi regida pelas exigências do mercado de trabalho partindo de políticas nacionalistas que buscaram princípios de eficiência, eficácia e qualidade oriundos dos meios empresariais e trazidos para o ambiente acadêmico por meio da busca por polivalência, domínio de estratégias cognitivas, aplicações de ferramentas conceituais e metodológicas para o desenvolvimento de um pensamento proativo e um sentido empreendedor (BARRÓN, 2005; SIMÓN, 2018).

Entretanto não se pode ignorar as características que constituem o profissional de Engenharia. Um trabalho recente realizado nos Estados Unidos da América concluiu que há três fatores que compõe a Identidade do engenheiro - (i) design, (ii) analysis, (iii) tinkering - que podem ser definidas respectivamente por: (i) interesse em criar e gerar processos inovadores por meio de experimentação ou prototipagem; (ii) identificar o necessário para resolver um problema ou concluir um projeto; (iii) a propensão de um indivíduo em entender o funcionamento de algo, desmontando e consertando as coisas (CHOE et al., 2019).

Em específico o engenheiro de produção é tratado como um indivíduo que desempenha função nos processos de produção sustentável, inovação e otimização de processos produtivos e de serviços (FLEURY, 2008). Nas Diretrizes Curriculares Nacionais da Engenharia de Produção se espera que o egresso seja capaz de reconhecer e solucionar problemas ligados ao projeto, operação e gerenciamento do sistema de produção, observando fatores humanos, econômicos, sociais e ambientais (BORCHARDT et al., 2009).

No final da primeira década deste século Borchardt et al. (2009) investigaram a demanda por capacidades específicas dos engenheiros de produção partindo de exigências das organizações. Naquele trabalho identificou-se carências como "previsão de cenários", "utilização de indicadores de desempenho", "análise financeira" e "entendimento da interação entre sistemas". Outras características como "ser capaz de identificar e resolver problemas" e "iniciativa" foram apontadas como fundamentais no perfil deste tipo de profissional. 

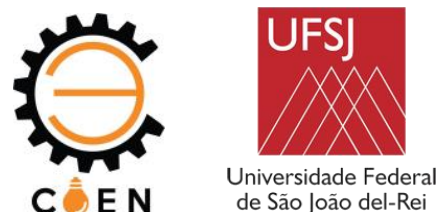

\section{RELATÓRIO DE EGRESSOS}

Algo realizado por diversas comunidades acadêmicas no mundo são os relatórios de egressos, uma descrição cujo objetivo é identificar o destino do estudante após a graduação. Nos Estados Unidos da América há um documento norteador com intuito de uniformizar a coleta de dados, é conhecida por Fist-Destination Survey Standards and Protocols (NACE, 2016). Na Austrália há o Graduate Outcome Surveys (GOS) responsável por avaliar o destino dos alunos de graduação (GOS, 2016).

Não há no Brasil órgão que centraliza dados gerais dos egressos, havendo algumas iniciativas como Mikishi; Silva (2017) que organizaram relatório para curso de Engenharia de Alimentos da Universidade de São Paulo, e de Mello (2018) que realizou levantamento analítico de formados em Engenharia de Produção pela Universidade Federal Fluminense. Para este trabalho decidiu-se então observar em quais condições se encontram os ex-alunos de Engenharia de Produção da UFSJ.

O levantamento de ex-alunos do curso de Engenharia de Produção da Universidade Federal de São João del-Rei iniciou-se por meio de uma lista de diplomas disponíveis na página da Divisão de Acompanhamento e Controle Acadêmico (DICON). Buscou-se pelos nomes no LinkedIn, rede social voltada para negócios, para identificar as empresas e cargos destes primeiros alunos e como uma consequência encontrou-se uma outra quantidade relevante de ex-alunos da universidade.

A lista final continha o nome de 113 concluintes do curso de Engenharia de Produção da UFSJ, foram excluídos dessa relação alunos cuja formação ainda não estivesse indicada como completa. Desta listagem 13 nomes não foram encontrados no LinkedIn, ou estavam com cadastros desatualizados apontando, por exemplo, que ainda estudavam na UFSJ. Assim a análise se deu com os 100 nomes restantes.

Uma vez que a primeira entrada no curso de Engenharia de Produção na UFSJ foi realizada em 2009, como a última avaliação do Ministério da Educação foi realizada no ano de 2017 é possível contabilizar a entrada de 540 estudantes. As indicações dos índices de evasão, contando a partir de 2013 quando era previsto a primeira formação até 2017, implica uma média de 80,12\% de abandono. Sendo assim, os 113 nomes buscados correspondem a 20,93\% da taxa de ingressantes, maior inclusive que os $19,88 \%$ estimados pelos índices do governo.

O primeiro apontamento é que dos 100 alunos formados pela instituição, cujos dados foram possíveis compilar, dez deles (10\%) informaram que estão atualmente sem ocupação e que buscam oportunidades no mercado. No seguimento foram agrupados considerando os setores nos quais as empresas em que os egressos estão empregados. A Tabela 1 contém os setores mais citados pelos formados.

Tabela 1. Setorização das empresas dos egressos

\begin{tabular}{|l|r|r|}
\hline \multicolumn{1}{|c|}{ Setor } & Frequência & Porcentagem \\
\hline Alimentício & 12 & $12 \%$ \\
\hline Educação & 9 & $9 \%$ \\
\hline Logística & 6 & $6 \%$ \\
\hline Startup & 5 & $5 \%$ \\
\hline Metalúrgico & 5 & $5 \%$ \\
\hline Siderurgia & 5 & $5 \%$ \\
\hline
\end{tabular}




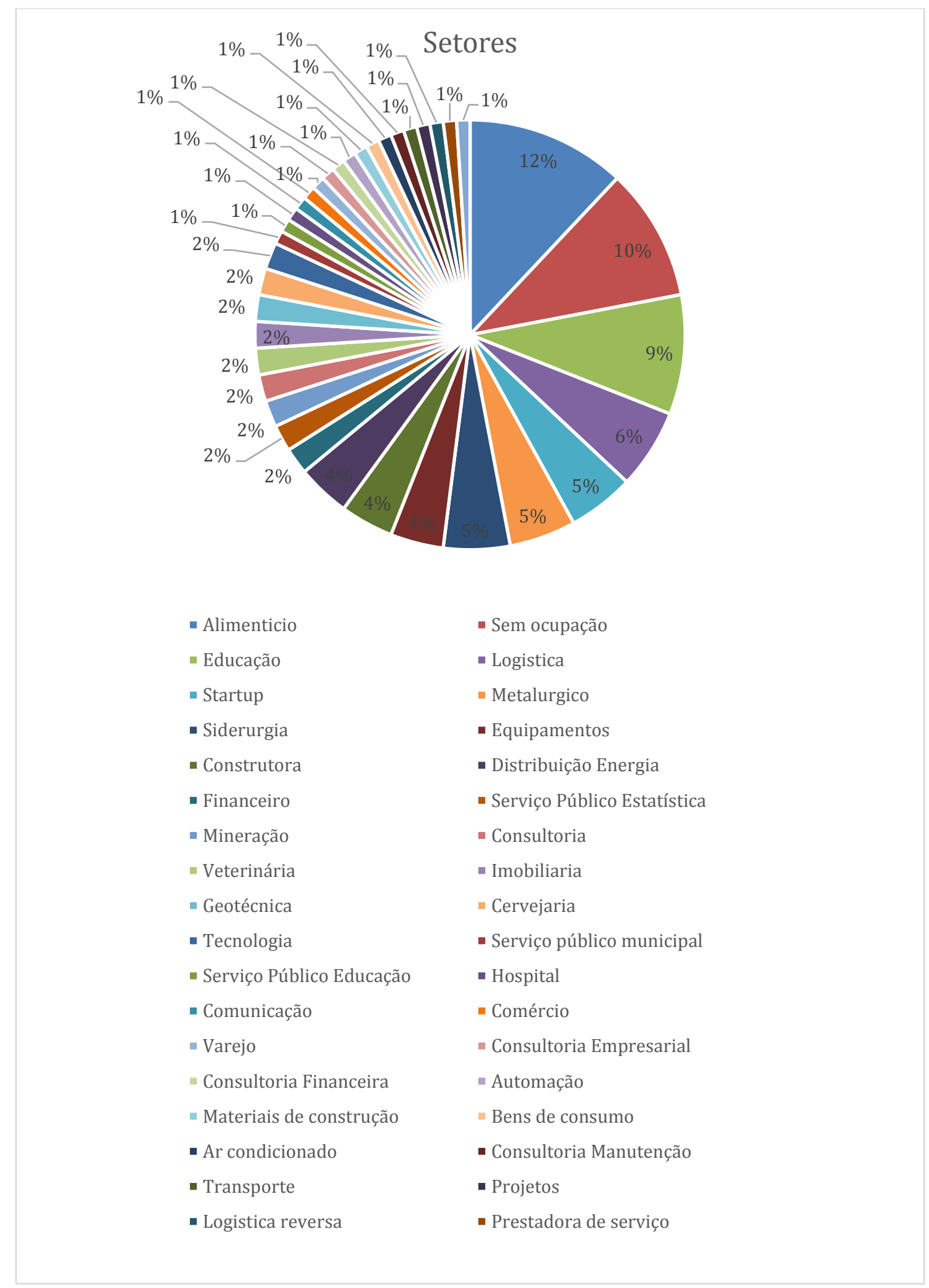

Figura 3. Gráfico de setores dos egressos 
Com estas informações é possível construir um gráfico indicador (Figura 3) com todos os setores, no total são 36 diferentes ramos de negócio, em que os ex-alunos estão inseridos. Neste gráfico também estão indicados os alunos que não têm ocupação atual. É interessante perceber o setor de startups entre os mais apontados, essa que é uma categoria que tem características tecnológicas voltadas a resolver problemas em diversos domínios e atualmente fator-chave para o desenvolvimento econômico em vários países (NCVA, 2018).

Na sequência, dispostos na Tabela 2, estão listados os cargos declarados. São 24 diferentes funções citadas pelos ex-alunos, as mais frequentes são os cargos de analistas e assistentes. Essas são duas funções que exploram das capacidades estimuladas e desenvolvidas durante o curso de engenharia. Em seguida aparecem os cargos de pesquisador, coordenador, gerente e especialista. Destas ocupações é importante destacar os cargos de liderança - coordenador e gerente - em que o profissional deve possuir habilidades complementares ao aprendizado técnico. A função de pesquisador, que a princípio pode surpreender, é continuação de uma das diretrizes propostas na graduação, a da investigação e desenvolvimento de novas tecnologias.

Tabela 2. Cargo listados alunos egressos

\begin{tabular}{|l|r|r|}
\hline \multicolumn{1}{|c|}{ Cargo } & Frequência & Porcentagem \\
\hline Analista & 19 & $19 \%$ \\
\hline Assistente & 12 & $12 \%$ \\
\hline Pesquisador & 5 & $5 \%$ \\
\hline Coordenador & 5 & $5 \%$ \\
\hline Gerente & 5 & $5 \%$ \\
\hline Especialista & 5 & $5 \%$ \\
\hline
\end{tabular}

Também foi possível construir um gráfico com todos os cargos declarados pelos ex-estudantes da UFSJ. Novamente é preciso indicar a porcentagem dos egressos que não ocupam funções profissionais atualmente. Assim montou-se um desenho com os ofícios (Figura 4), sendo possível compreender em quais colocações o mercado exigiu que se adequassem esses recém-formados. 


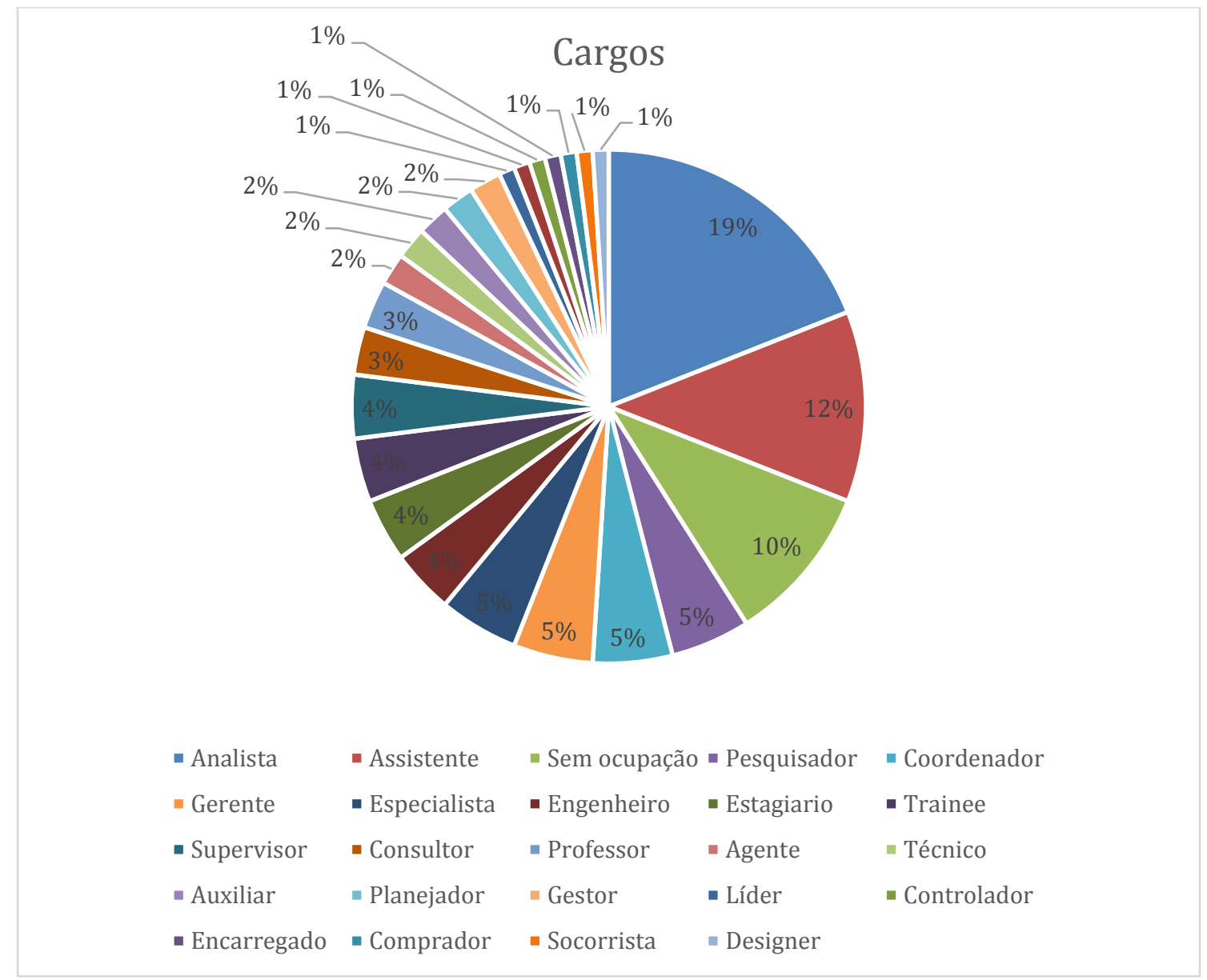

Figura 4. Gráfico com os cargos dos alunos egressos

\section{CONCLUSÕES}

Este trabalho realizou um levantamento sobre a situação atual dos egressos da Engenharia de Produção da Universidade Federal de São João del-Rei. A intenção é atualizar as demandas do mercado em comparação com o que se discute sobre a formação do engenheiro em trabalhos no Brasil e no exterior.

Essa investigação vai no sentido de criar argumentos para novas propostas de disciplinas optativas e complementares. Não apenas para serem ofertadas pelos departamentos diretamente ligados ao curso, mas buscados em outros cursos com base nas ciências sociais, humanas e, haja vista que há profissionais empregados em hospitais, até mesmo nos cursos de ciências médicas da universidade.

Obviamente os ideais de um profissional de engenharia cada vez mais multifacetado e com visões suplementares aos conhecimentos técnicos disponíveis na sua formação também está intrinsicamente relacionado às ações do acadêmico, tendo em vista que esse deve investir dedicadamente à própria formação, colocando-se em atividade condizente de aprendiz. A importância 
e função de cada disciplina mostra-se condição fundamental na função coletiva da formação do engenheiro.

Como recomendações de futuros estudos estão em aprofundar nas razões e elementos que constituem na alta taxa de evasão dos cursos de engenharia de produção em todo o país. Há neste texto uma indicação suspeita sobre o quanto a recente crise política e econômica possa ter influenciado nessa questão, entretanto nada pode ser afirmado sem que haja um levantamento de dados suficiente para sustentar qualquer alegação deste tipo.

Outra recomendação à Coordenadoria do Curso de Engenharia de Produção, e não somente a este órgão, mas às outras secretarias dos vários cursos da UFSJ, em recolher dados frequentes dos próprios egressos. Devido ao cenário atual do ensino superior brasileiro é necessário formar uma comunidade forte de membros que não apenas conhecem as organizações, mas que possam contribuir com ela de várias maneiras.

\section{AGRADECIMENTOS}

O presente trabalho foi realizado com apoio da Coordenação de Aperfeiçoamento de Pessoal de Nível Superior - Brasil (CAPES) - Código de Financiamento 001.

\section{DIREITOS AUTORAIS}

Os autores são os únicos responsáveis pelo conteúdo das informações contidas neste artigo.

\section{REFERÊNCIAS}

ACOFI. El ingeniero colombiano del año 2020: retos para su formación. . Bogotá: Asociación Colombiana de Facultades de Ingeniería, 2007.

BARRÓN, Concepción. Formación de profesionales y política educativa en la década de los noventa. Perfiles Educativos, v. 27, n. 108, p. 45-69, 2005.

BATTISTI, Isabel Koltermann; NEHRING, Cátia Maria. A formação acadêmica do engenheiro: produto de uma atividade coletiva. Revista Ibero-Americana de Estudos em Educação, v. 14, n. 2, p. 543-558, jun. 2019.

BITTENCOURT, Hélio Radke; VIALI, Lorí; BELTRAME, Ediliane. A Engenharia de Produção no Brasil: Um panorama dos cursos de graduação e pós-graduação. Revista de Ensino de Engenharia, v. 29 , n. 1, p. 11-19, 2010.

BORCHARDT, Miriam et al. O perfil do engenheiro de produção: a visão de empresas da região metropolitana de Porto Alegre. Produção, v. 19, n. 2, p. 230-248, 2009.

BRASIL. Resolução CNE/CES 11/2002, "Institui Diretrizes Curriculares Nacionais do Curso de Graduação em Engenharia”., 2002.

CARUSO, Ernesto. Ponta do Calabouço - início do século XX: berço fardado dos doutores. Revista do Clube Militar, v. LXXXI, n. 430, p. 14-16, out. 2008. 

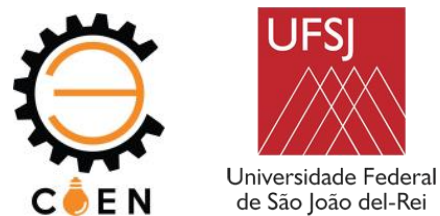

CHOE, Nathan H. et al. Professional Aspects of Engineering: Improving Prediction of Undergraduates' Engineering Identity. Journal of Professional Issues in Engineering Education and Practice, v. 145, n. 3, p. 04019006, 1 jul. 2019.

DAMIÁN, Javier. Professional Identity, Social Recognition and Entering the Workforce of the University Student with Hybrid Education. Propósitos y Representaciones, v. 2, n. 2, p. 45-76, 2016.

FIOLHAIS, Carlos; SIMÕES, Carlota; MARTINS, Décio. História da ciência luso-brasileira: Coimbra entre Portugal e o Brasil. [S.1.]: Imprensa da Universidade de Coimbra / Coimbra University Press, 2013.

FLEURY, Afonso. O que é Engenharia de Produção? Introdução à Engenharia de Produção. Rio de Janeiro: Elsevier, 2008. .

GOS. Graduate outcomes survey methodological report. . [S.1.]: QUALITY INDICATORES FOR LEARNING AND TEACHING, 2016.

IBGE. Índice Nacional de Preços ao Consumidor Amplo - IPCA e Índice Nacional de Preços ao Consumidor - INPC. . [S.1: s.n.], 2018. Disponível em: <https://ww2.ibge.gov.br/home/estatistica/indicadores/precos/inpc_ipca/defaultinpc.shtm>. Acesso em: 14 jun. 2019.

INEP. Sinopse Estatística da Educação Superior. . Brasilia: Instituto Nacional de Estudos e Pesquisas Educacionais Anísio Teixeira, 2018. Disponível em: <http://portal.inep.gov.br/web/guest/sinopsesestatisticas-da-educacao-superior>. Acesso em: 14 jun. 2019.

MELLO, Thomaz Sento Sé. Uma análise da colocação profissional dos egressos de Engenharia de Produção Da UFF - Niterói durante o cenário da crise iniciada em 2014. 2018. 57 f. Monografia Universidade Federal Fluminense, Niterói, 2018.

MIKISHI, Fausto; SILVA, Vivian. Mapeamento dos egressos do curso de Engenharia de Alimentos da Universidade de São Paulo: Por onde anda você? [S.1.]: USP, 2017. (Portal de Livros Abertos).

NACE. First Destination Executive Summary. . [S.l.]: NATIONAL ASSOCIATION OF COLLEGES AND EMPLOYERS, 2016.

NASCIMENTO, Paulo A. et al. Escassez de engenheiros: realmente um risco? Revista Radar, v. 6, n. Publicação do Instituto de Pesquisa Economica Aplicada, 2011.

NCVA. Venture Monitor. . [S.1.]: National Venture Capital Association, 2018.

OLIVEIRA, Vanderlí Fava De. Retrospecto sobre a formação em Engenharia. Educação em Engenharia: Evolução, Bases e Formação. 1ed. ed. Juiz de Fora: FMEPRO, 2010. v. 1. p. 16-31.

OLIVEIRA, Vanderlí Fava De et al. Um estudo sobre a expansão da formação em engenharia no Brasil. Revista de Ensino de Engenharia, v. 32, n. 3, p. 37-56, 2013. 

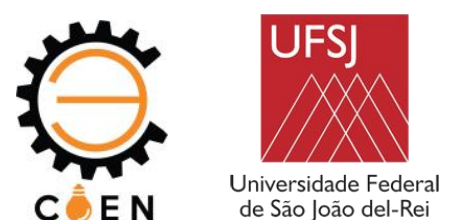

RUIZ, Estela. Ingenieros en la industria manufacturera. Formación, profesión y actividad laboral. México: Plaza y Valdés - UNAM, 2004.

RUIZ, Estela. La era pos-industrial y la formación de ingenieros. Perfiles Educativos, v. 79, n. 80, p. 58-79, 1998.

SÁEZ, Fernando. Futuros ingenieros híbridos. Revista BIT, v. 144, p. 7-9, 2004.

SIMÓN, Javier Damián. Yo estudio para ser ingeniero: ¿para qué cursar administración y contabilidad? Propósitos y Representaciones, v. 6, n. 2, p. 453-540, jul. 2018.

UNESCO. Engineering: Issues, challenges and opportunities for development. . France: United Nations Educational, Scientific and Cultural Organization, 2010.

\section{REPORT OF THE GRADUATES AT PRODUCTION ENGINEERING OF UFSJ}

ABSTRACT: This article is a survey of the graduates at Production Engineering course of the Federal University of São João del-Rei. It discusses the evolution of engineering in Brazil, from the establishment of the first school of the type, still in the colonial period, to the changes caused by the evolution of society over time, until the establishment of the first faculties of Full Production Engineering. All this transformation also brought about a modification of the required profile of the engineering professional, requesting from the newly formed skills, attitudes and knowledge different from just technical understanding. For this work we used data obtained through official reports from the federal government, analysis of the Pedagogical Project of the Course, and collection of data obtained by means of dissemination in public social network. The information was gathered to facilitate the planning of the next years of graduation, makes this work a guiding document for future directions of higher education aimed at enabling an increasingly multidisciplinary professional.

KEYWORDS: engineering, education, production, multidisciplinarity, graduates 